\title{
European National (Time) Transfer Accounts
}

\author{
Tanja Istenič ${ }^{1}$, Bernhard Hammer ${ }^{2}$ and Alexia Prskawetz ${ }^{2,3, *}$
}

\section{Introduction: The generational economy and National Transfer Accounts}

The goal of the National Transfer Accounts (NTA) project is to improve our understanding of the economic consequences of demographic changes by introducing demographic information into the System of National Accounts (SNA). As part of the AGENTA research project (http://www.agenta-project.eu/), NTA datasets were compiled for 25 European countries and the base year 2010. The aim of this paper is to introduce the general concept of NTA, and to provide an overview of the European NTA data and the data explorer at www.wittgensteincentre.org/ntadata.

Age is one of the main determinants of individuals' economic behaviour. In general, people experience three different economic phases in their life course. Working-age individuals are typically able to finance their own consumption by producing more than they consume. In contrast, at the youngest and oldest ages, people's consumption usually exceeds their labour income (Lee and Mason 2011b). The gap between consumption and labour income can be financed by age reallocations in the form of private transfers (e.g., transfers from parents to children), public transfers (e.g., publicly financed pensions and education), or assetbased reallocations resulting from participation in capital and financial markets (Mason et al. 2006). In contemporary societies, periods of economic dependency are gradually being extended as the young are spending more time in education and the elderly are living longer.

Measuring age reallocations is useful for understanding the intergenerational economy and the organisation of intergenerational support; i.e., how the gap between consumption and labour income is financed in childhood and in old

\footnotetext{
${ }^{1}$ University of Ljubljana, School of Economics and Business, Slovenia

${ }^{2}$ Wittgenstein Centre for Demography and Global Human Capital, Vienna Institute of Demography, Austrian Academy of Sciences, Vienna, Austria

${ }^{3}$ TU Wien, Austria

*Correspondence to: Alexia Prskawetz, afp@econ.tuwien.ac.at
} 
age. Introducing the age dimension into the SNA is especially relevant in light of the unprecedented demographic changes that Europe has been facing in the past few decades. Population ageing puts the system of intergenerational flows under pressure, as the share of the population made up of inactive elderly people whose pensions, health care, and long-term care have to be financed by a shrinking labour force increases (Hammer et al. 2015). Therefore, population ageing requires changes in both the public and the private intergenerational reallocation of resources. Understanding the age patterns of production, consumption, and intergenerational reallocations is necessary when analysing the effectiveness of alternative policies, as some government policies can be advantageous for certain generations, but burdensome for others.

Accounting systems such as the SNA do not offer information on age or the generational aspects of the aforementioned changes. Our ability to assess the economic consequences of population ageing is, therefore, very limited. The National Transfer Accounts (NTA) have been developed to fill this gap (United Nations 2013). NTA constitute an accounting framework that provides information on the allocation of income among age groups. NTA data consist of age profiles, which are the age-specific averages of labour and asset income, transfer benefits and contributions, consumption, and savings. By focusing on the age dimension, NTA shed light on the effect of the changing age structure on different macroeconomic categories. Thus, NTA can be seen as a valuable tool for addressing some of the major challenges of modern societies (United Nations 2013). An overview of the NTA methodology and data is provided in Lee and Mason (2011a), d'Albis \& Moosa (2015), and in the United Nations (2013).

Although the services provided through unpaid household labour make up a large share of intergenerational reallocations, they are neither included in National Accounts, nor in the basic NTA framework. The production and transfer of unpaid services within households are included in the NTA framework through the socalled National Time Transfer Accounts (NTTA) (Donehower 2019).

The compilation of NTA is organised within the global NTA project, which is a collaboration of research teams in more than 60 countries. Usually, the NTA for each country are compiled by country-specific research groups. However, European members of the NTA project joined forces to launch the AGENTA project, which aims to explain past developments and to forecast future trends in taxes and public transfers in light of the demographic changes in the European Union. A primary goal of the project has been to set up gender-specific NTAs for all EU countries using publicly available and harmonised data from Eurostat. The European NTA 2010 data provide comprehensive and detailed age- and gender-specific economic data on income, transfers, consumption, and savings. A detailed description of the European NTA and NTTA data is found in Istenič et al. (2016) and Vargha et al. (2016). The data can be accessed at www.wittgensteincentre.org/ntadata (see the Appendix). 


\section{European National Transfer Accounts (NTA) 2010}

European National Transfer Accounts (NTA) for 2010 have been set up for $25 \mathrm{EU}$ countries. NTA could not be created for Croatia, Malta, or the Netherlands because of missing data.

Three distinct steps are distinguished in the calculation of NTAs. The first step is to derive the values of income, transfers, consumption, and savings for the total economy from the European System of Accounts (ESA) and related sources. The second step is to calculate the age- and gender-specific averages of different economic categories using survey and/or administrative data. We use EU Statistics on Income and Living Conditions (EU-SILC) as the main survey data source for estimating income-related variables, and Household Budget Survey (HBS) data for creating private consumption age profiles. As the unit of analysis in NTA is an individual, we use survey data reported at the individual level whenever possible. Administrative data sources are primarily used to calculate flows mediated by the public sector. The third step involved in compiling NTA consists of estimating the intra-household transfers (i.e., transfers flowing within the same household). NTA rely on the indirect estimation of intra-household transfers, because these transfers are not captured in National Accounts or survey data. The European NTA Manual (Istenič et al. 2016) describes the steps, procedures, and assumptions used in obtaining the NTA results, which can be downloaded at . In the following, we review the main methodology and the data sources used in compiling the European NTA data.

NTA measure the reallocation of resources between age groups. In the NTA context, the term "life-cycle deficit" (LCD) is used to refer to the difference between the age-specific averages of consumption and labour income. Children and elderly individuals have a positive LCD, as their consumption exceeds their labour income. The working-age population has a life-cycle surplus, as their labour income exceeds their consumption. The NTA accounting identity states that the LCD equals the sum of net transfers plus asset income less savings. Asset income less savings are usually combined to form a single component, called asset-based reallocations. Net transfers are defined as the difference between transfer inflows and transfer outflows.

\subsection{Labour income}

Labour income makes up the largest share of aggregate income, and varies considerably by age. It includes employee compensation (combined with the employer's social contributions) and the returns to labour of self-employed workers. The latter are assumed to account for two-thirds of mixed income. The gender-specific age profiles for labour income are estimated using EU-SILC survey data, in which each worker's wages, self-employment income, and employer-provided social contributions are reported separately for each individual. For most EU member states, the income is recorded for the calendar year preceding the interview. Thus, to 
estimate the income-related variables for the year 2010, we use data from EU-SILC 2011, in which the variable age is reported at the end of the income reference period (i.e., for the year 2010).

\subsection{Consumption}

Consumption is separated into private and public consumption. Both private and public consumption are further divided into education, health, and other forms of private or public consumption. These distinctions are motivated by the huge age-specific variation in these components. The private consumption aggregate controls are calculated using the ESA 2010 and consumption expenditure by the Classification of Individual Consumption by Purpose (COICOP). For public consumption, data on expenditure according to the Classification of the Functions of Government (COFOG) are used to calculate the aggregate values of the public consumption subcategories.

The gender-specific age profiles for private consumption are mainly based on the HBS survey data, with the reference year of 2010. The HBS includes the main characteristics for all the household members, but the data on consumption expenditures are collected at the household level only. Therefore, the allocation rules are used to allocate consumption among the household members. Private consumption other than for education and health is allocated within households using the ad-hoc allocation rule, based on the modified Deaton's (1997) equivalence scale. This rule assumes that people aged 20 or older have the same consumption share, which is set to one. For children younger than age four, a consumption share of 0.4 of that of an adult is assumed. For children between the ages of four and 20, the consumption share increases linearly from 0.4 to 1.0 of the consumption of an adult.

The age allocation of private health consumption within a household is based on an equivalence scale estimated with a regression function. The equivalence scale of health consumption is calculated by regressing the health expenditures of a household on the number of household members of a specific age group. As treating each age group from zero to $80+$ separately would mean losing too many degrees of freedom, 10-year age groups are used. The regression coefficient is equal for all individuals of the same age group, and is used as a share when allocating total household expenditures on health to individual members.

To allocate household expenditures on education among the household members, we combine data on level-specific expenditures with the information on the level of education in which an individual is enrolled. To do so, we assume that the unit costs are equal for all household members enrolled in a specific level of education, regardless of age.

The age profiles for public consumption are estimated by distinguishing between individual public consumption and collective public consumption. Collective public consumption includes consumption of public goods such as national security, public 
administration, public infrastructure, and street lighting. These components are allocated equally to all individuals in all of the age groups. Like private consumption, public consumption is divided into three main categories: education, health, and areas other than education and health.

To create the age profile of public education consumption, we allocate total public education expenditures among the different educational levels and combine these data with enrolment data; disaggregated by age and level. We distinguish the educational levels using the International Standard Classification of Education (ISCED). As in the case of private education consumption, the underlying assumption is that the unit cost of public education is equal for all students enrolled at a specific level, regardless of age.

There is no administrative data source that offers comparable data on public health expenditures for all EU countries. Therefore, we use the pre-calculated age profiles of health care consumption for one-year age groups from the Ageing Working Group (AWG) to estimate the public health consumption age profiles. We take the profiles from the AWG report 2012 (European Commission 2012) and adjust them to the country-specific macro controls for 2010.

Next, we assume that the COFOG categories "old age" and "sickness and disability" have the same distributions as publicly financed long-term care; also based on AWG data. By contrast, "unemployment", "family and children", and "housing" public consumption age profiles are calculated by taking the age profiles of the corresponding cash categories of public transfer inflows, as explained below.

In Figure 1, we present gender-specific labour income and total consumption age profiles. To enable us to compare the results across the countries, the data are presented relative to the average labour income of individuals between the ages of 30 and 49. The generation of labour income (YL) is concentrated at ages 20-60, albeit with considerable differences between men and women in most of the countries. The gender differences are mainly attributable to differences in the participation rates of men and women, as well as to the gender pay gap. Whereas the labour income age profile has a typical inverted U-shaped curve, the consumption (C) profile is rather stable across ages - with the exception of a peak around age 15 due to high levels of consumption of public education, and another peak in old age due to high levels of consumption of public health services. Figure 1 also shows that the gender patterns differ markedly across countries. For example, in Slovenia, women generate almost the same average labour income as men; while in Austria, women generate only about one-third of total labour income, as the large differences in the labour income levels for men and women in that country clearly illustrate.

\subsection{Public transfers}

Public transfer inflows refer to the flows that are mediated by the government, including both in-kind and in-cash transfers received by individuals. By definition, public transfers in kind are equal to the public consumption explained above. 
Figure 1:

Age- and gender-specific labour income and consumption, EU25 average, Slovenia, Sweden and Austria, 2010
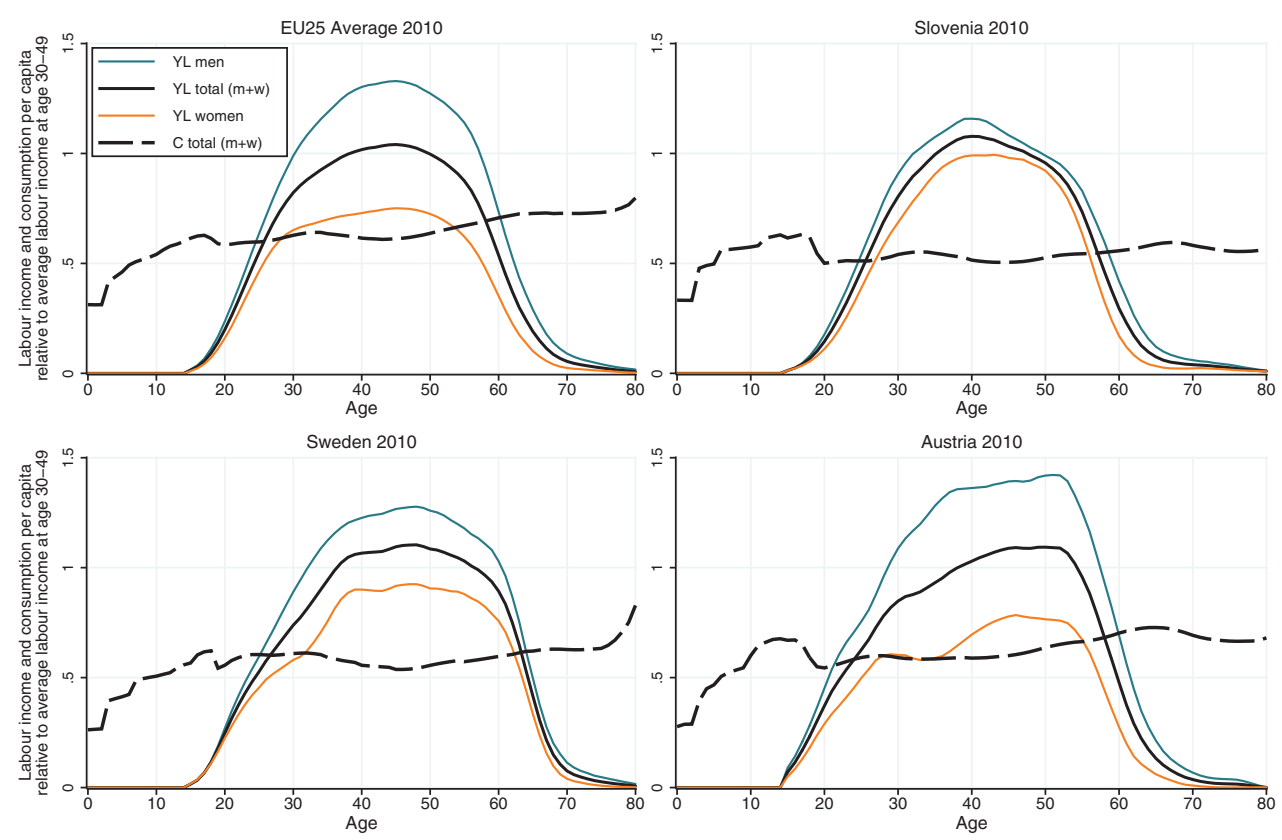

Source: Istenič et al. 2016 (retrieved from www.wittgensteincentre.org/ntadata).

Public transfer inflows in cash include monetary transfers from the government to individuals, such as public pensions. Public transfers are divided by function into the three subcategories: education, health, and pensions. The remaining types of in-kind and in-cash public transfers (not disaggregated into the subcategories) are aggregated into one category of other in-kind and other in-cash transfer inflows. This category includes transfers related to unemployment, family and children, housing, and other benefit programs.

The aggregate values of public transfer inflows in cash by purpose are based on data from the ESA 2010 and the European System of Integrated Social Protection Statistics (ESSPROS). Public transfers in cash are direct payments from the government to individuals, and are therefore reported in the survey data. Whereas sickness, disability, old age, survivors', and unemployment benefits are reported at the individual level in the EU-SILC, family and child benefits and housing benefits are reported at the household level, and are therefore distributed among the household members. The family- and child-related allowances are assigned to all adults in the household, whereas the housing allowances are assigned to the household head only. 
Figure 2:

Age- and gender-specific public transfer inflows (benefits) and public transfer outflows (contributions), EU25 average, 2010

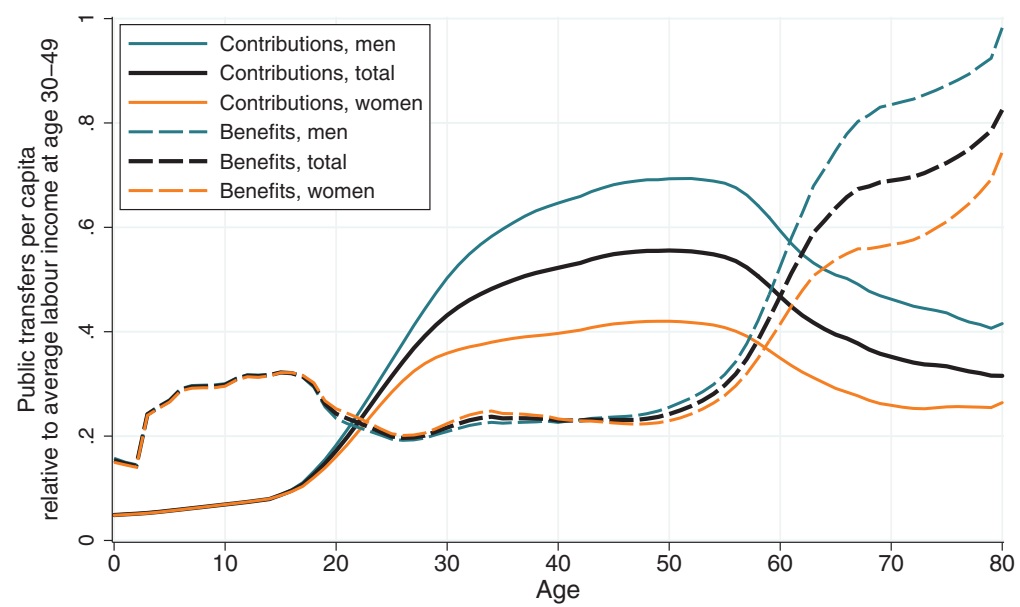

Source: Istenič et al. 2016 (retrieved from www.wittgensteincentre.org/ntadata).

Public transfer outflows measure the flows of economic resources from the private sector (individuals or firms) to the public sector. They are used to finance public transfer benefits, public asset income (if negative; e.g., interest on public debt), or public savings. Public transfer outflows consist of taxes, social contributions, and other revenues paid to the government. In the NTA, public transfer outflows are distinguished by their source; i.e., the activity that is being taxed. We thus distinguish between taxes on asset income, labour income, and consumption; and between social contributions paid by pensioners and social contributions paid by employers and employees. The aggregate controls for public transfer outflows are estimated based on the Eurostat data on "Structure of taxes by economic function". The age patterns of these categories come from the age profiles of taxed economic activities. For example, the age profile of taxes on labour income is based on the labour income age profile, and the age profile of taxes on the consumption of goods and services is based on the private consumption age profile.

Figure 2 shows the age- and gender-specific public transfer inflows and outflows for the EU-25 countries. The results are again normalized (i.e., presented relative to the average labour income for ages 30-49). At young ages, the total public inflows closely follow the age pattern of in-kind public inflows (with the prevailing component being education). At working ages, the public transfer inflows are mostly in the form of collective consumption, and are therefore rather constant. At old ages, the public transfer inflows are especially high, and include in-cash transfers in the form of pensions, as well in-kind transfers in the form of health and long-term care. 
The shapes of the age profiles of public transfer inflows and outflows differ greatly, as the ages of the main beneficiaries of public transfers differ from the ages of most taxpayers and payers of social contributions. The age profile of total public transfer outflows increases rapidly starting around the age of 20 , when young adults are entering the labour market. The peak is observed at prime ages, when the public outflows are high due to social security contributions and payroll and workforce taxes. The public outflows at young ages are mainly in the form of taxes on the consumption of goods and services. At old ages, the public outflows are largely in the form of taxes on the consumption of goods and services, taxes on asset income, as well as taxes and social contributions paid on pension benefit. As the transfer outflows are higher for men than for women, men tend to receive higher transfer inflows, mostly in the form of pensions, at higher ages.

Net transfers are defined as the difference between transfer inflows and transfer outflows, and are positive at young and old ages, when individuals are net dependents on private and public transfers. By contrast, at working ages, individuals are net supporters of both public and private transfers. In the following, we present the methodological framework for constructing private transfer age profiles.

\subsection{Private transfers}

Private transfers include transfers between households (inter-household transfers) and transfers within households (intra-household transfers). The NTA private transfers refer to inter vivos transfers, and thus exclude capital transfers such as bequests. Inter-household private transfers include direct transfers between households (e.g., alimony payments and gifts) as well as indirect household transfers mediated by the non-profit institutions serving households (e.g., donations). At the aggregate level, the difference between inter-household transfer inflows and outflows is defined as the net private transfers from the rest of the world (ROW). The age profiles of interhousehold transfers are based on the EU-SILC data. As there are no available survey data on the transfers received or given at the individual level, we assume that all of the inter-household transfer inflows flow to the household head, and that all of the inter-household transfer outflows flow from the household head.

Among the main contributions of the NTA methodology are the estimates of intra-household private transfers. The aggregate value of net intra-household private transfers equals zero, as intra-household transfers represent transfers within the same household. Therefore, at the aggregate level, the intra-household transfer inflows equal the intra-household transfer outflows. As there are no micro-data on intra-household transfers, we estimate them indirectly using the household structure from the EU-SILC and the age profiles that have already been calculated. In general, intra-household transfers represent the difference between age-specific disposable income and age-specific consumption. The household member whose consumption exceeds his/her disposable income is in deficit, and has to receive transfers from other household members who have a surplus. If the total deficit of all of the 
Figure 3:

Age-specific private transfers, EU25 average, 2010

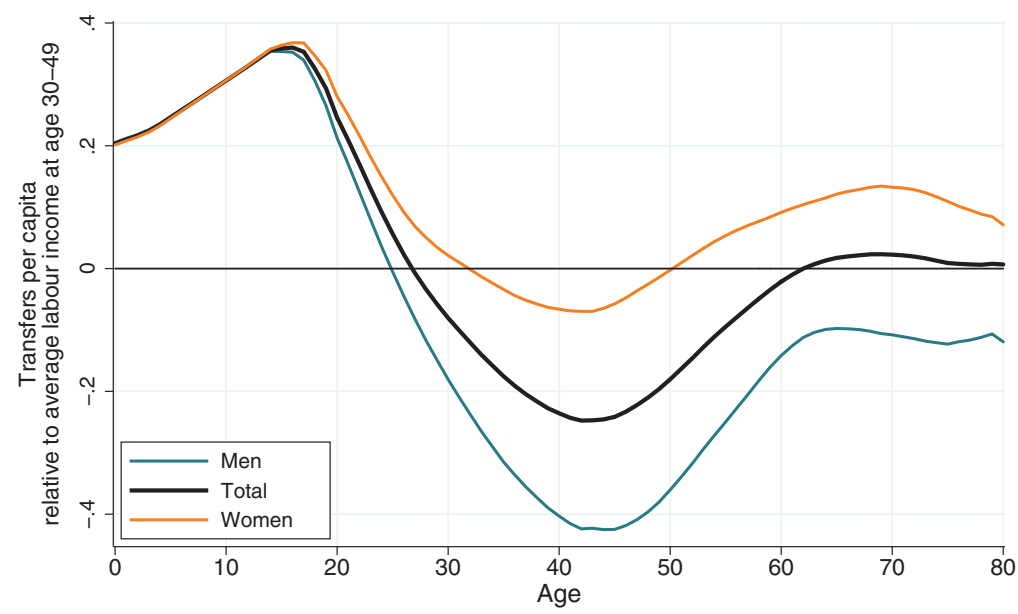

Source: Istenič et al. 2016 (retrieved from www.wittgensteincentre.org/ntadata).

household members exceeds the household's total surplus, the household head has to finance this gap through asset-based reallocations; for example, by borrowing assets.

Figure 3 shows private transfer patterns by age and gender. The main direction of private transfers is from parents to their children. Net private transfers to and from the elderly population are close to zero. In all of the adult age groups we observe transfers from men to women. As we will see in the next section, women tend to focus on unpaid work, while men tend to specialise in paid work. A man may compensate his female partner for her "unpaid" work via intra-household transfers.

Figure 4 combines public and private transfers. Children finance their life cycle deficit through private transfers from their parents and through public transfers, such as publicly provided education. For elderly individuals, private transfers play a negligible role. Older people are the main recipients of public transfers, primarily in the form of pensions.

\subsection{Asset-based reallocations}

The LCD that is not covered by transfers is financed by asset-based reallocations (ABR). ABR are calculated as asset income (the sum of capital and property income) less savings. Individuals with asset income have an inflow that can be used for consumption or transfers in the accounting period. Dissaving (negative savings) has the same effect, and increases individuals' consumption or transfer payments in the accounting period. 
Figure 4:

Age-specific net public and private transfers, EU25 average, 2010

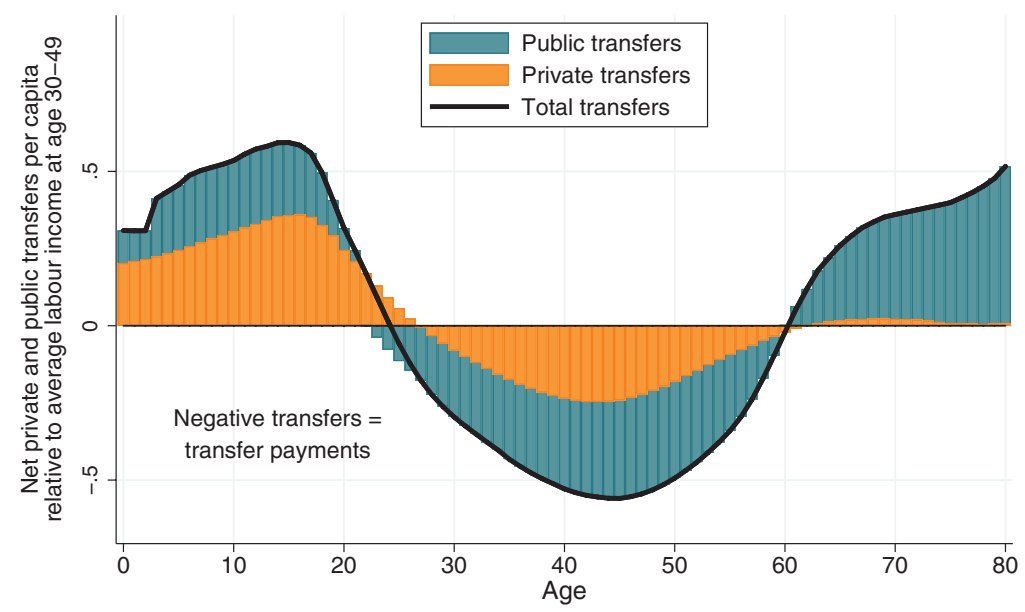

Source: Istenič et al. 2016 (retrieved from www.wittgensteincentre.org/ntadata).

Public ABR equal the public transfer deficit or surplus. A public transfer deficit is generated when the taxes, social contributions, and other current transfers paid by the residents are not sufficient to cover the public transfer inflows to the residents and the net public transfers to the ROW. The government therefore has to cover the public transfer deficit through positive ABR (i.e., issuing new debt). When the transfers received by the government are high enough to cover its expenses, a transfer surplus is generated. To compile the age profiles of public asset income and public savings, we use the age profile of public transfer outflows (generated as the sum of taxes, social contributions, and other government revenues). The logic behind this assumption is that taxpayers are defined as those individuals whose payments cover the public deficit, or who benefit from the surplus.

Private ABR include the net operating surplus of households and corporations, the capital share of mixed income, and taxes less subsidies on capital income. They also include property income, such as income from interest, dividends, and rents. For the age profiles of the capital income of corporations and the property income, we use the age averages of asset income variables reported in EU-SILC. For the income from owner-occupied housing, we use the age profile of imputed rents. Finally, for the unincorporated enterprise income, we take the age profile of earnings from selfemployment.

Figure 5 gives an overview of the main NTA components. The yellow area represents labour income, while the orange line represents consumption. The difference between labour income and consumption in childhood and in old age is financed by transfers and by ABR. Likewise, the surplus of labour income over 
Figure 5:

Labour income, consumption, transfers and asset-based reallocations, 2010
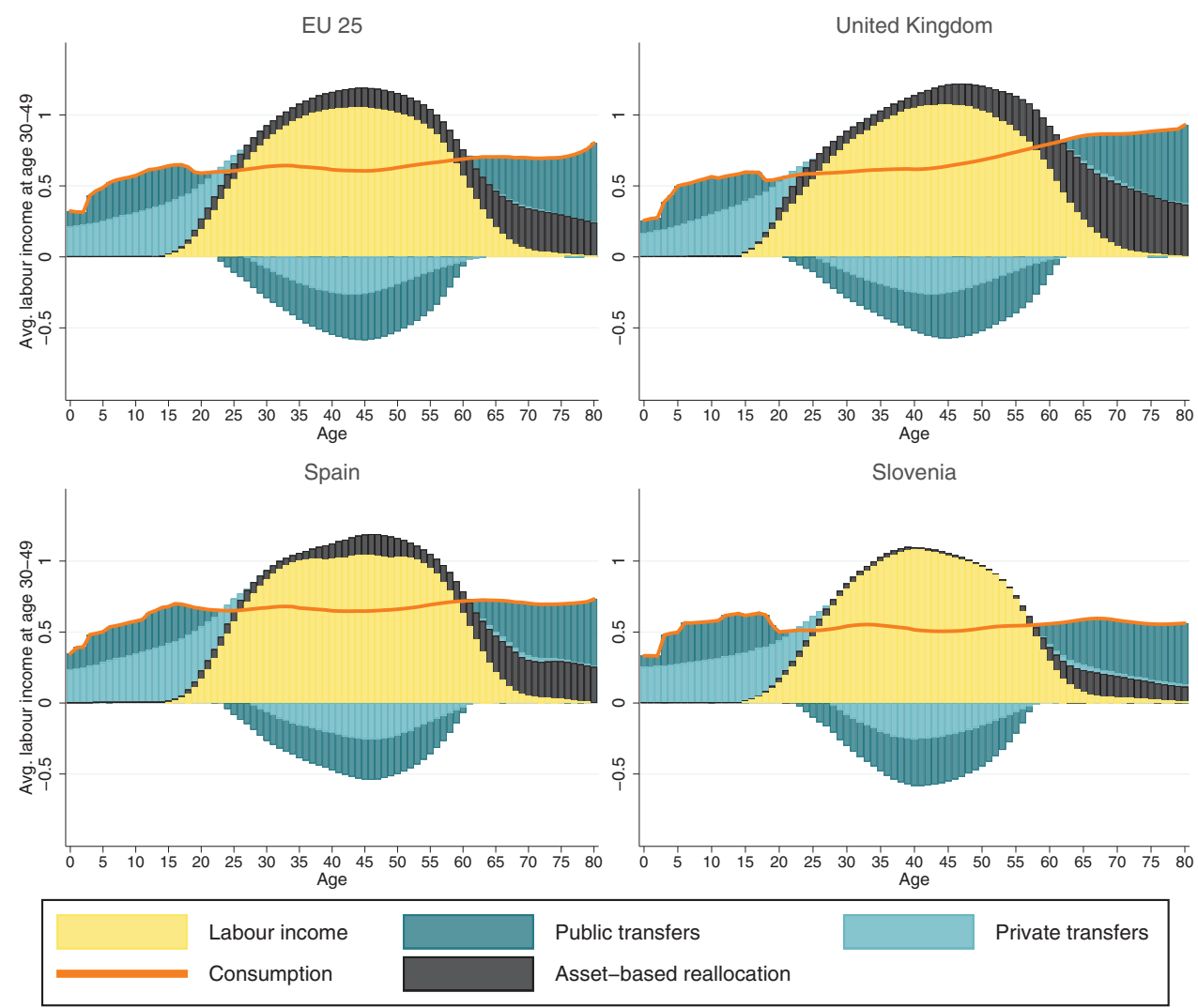

Source: Istenič et al. 2016 (retrieved from www.wittgensteincentre.org/ntadata).

consumption at working ages is used for transfers or ABR. The figures for the UK, Spain, and Slovenia show the differences between countries in the relative importance of assets for old-age provision. In the UK, a large share of the LCD is covered by private ABR, while in Slovenia, this share is extremely small.

Figure 6 shows the age profiles of the LCD that equal the total reallocations received or paid by an average individual of a specific age group. The term total reallocations refers to the sum of net transfers and ABR. Countries are selected based on their geographical positions and institutional characteristics. The country with the shortest period in which individuals are net supporters is Greece, as, on average, labour income in that country exceeds consumption only between ages 32 and 54. The prolonged period of dependency among young people in Greece is enabled by high net private transfers. In Sweden, by contrast, the average period of time people stay in the labour market is five years longer than it is in most 
Figure 6:

Life cycle deficit, 2010

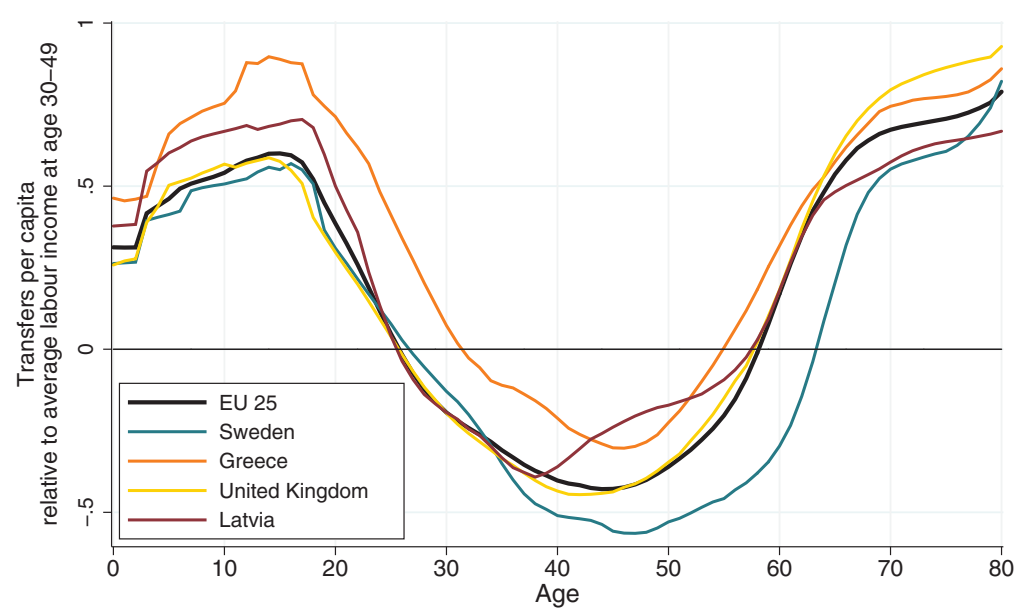

Source: Istenič et al. 2016 (retrieved from www.wittgensteincentre.org/ntadata).

other EU countries. Thus, workers in Sweden are able to support the young and the elderly over a longer age span than their counterparts in any other EU country; i.e., between the ages of 27 and 63. Moreover, while public pensions are modest relative to the average labour income in Latvia, they are high relative to the average labour income in Greece. The large net transfers received by the elderly in the UK are mainly the result of high levels of public health consumption, whereas the hump at the highest ages in Sweden is mainly attributable to the generous long-term care benefits Swedish individuals receive.

\section{Measuring transfers through unpaid household work: National Time Transfer Accounts}

Services provided to other household members, such as care, cooking, shopping, and cleaning, represent a large share of production and intergenerational transfers. Household satellite accounts extend the measures of national income by providing the value of services produced by households for their own consumption. Production in the household is not recorded in official statistics or by surveys, and there is no market mechanism that values it. Therefore, the output of unpaid household production is usually measured by valuing time as the most important input in household production. NTTA incorporate age, intergenerational transfers, and consumption of services produced by unpaid work into the Household Satellite Accounts framework (Donehower 2019). Thus, NTTA extend the basic NTA framework by adding 
age- and gender-specific estimates of production, transfers, and consumption of services produced by unpaid work. Because the bulk of household production is carried out by women, and because it is not included in national accounts, these calculations are crucial to making women's total economic contribution and the resources flowing to children more visible.

The main steps involved in estimating NTTA are (1) measuring the time spent on household production activities in time use surveys; (2) finding appropriate wages to impute the value of the time spent on the chosen activities; and (3) estimating consumption of household labour by allocating the goods and services produced through unpaid work to the members of the household.

Based on two publicly available European harmonised sources of data - the Harmonised European Time Use Survey (HETUS) Web Application and the Multinational Time Use Study (MTUS) - we compiled a comparative dataset on National Time Transfer Accounts (NTTA). For 14 EU countries, the age profiles are calculated based on the HETUS data. NTTA for three more countries are based on MTUS data. Our dataset comprises cross-sectional harmonized comparative European NTTA age profiles for 17 European countries representing about 84 per cent of the population of the European Union. For selected European countries we also provide historical NTTA data. To obtain NTTA age profiles in monetary terms we also introduce the pricing of household production.

We use the advantage of HETUS, where activities and other important variables are already standardized. However, the HETUS data enables users to calculate user defined statistical tables, but it is not a micro-database per se. To estimate the consumption of household labour requires the use of additional assumptions and thus a bit modified Donehower's (2019) methodology. The European NTTA Manual (Vargha et al. 2016) describes the steps, procedures and assumptions applied in creating the NTTA results and can be downloaded at http://www.agenta-project.eu/ Jacomo/upload/publications/d-2.3-submitted.pdf.

\subsection{Household production}

The activities included in the household production are selected based on the thirdperson principle, presenting those activities that can be done by a third person on behalf of the respondent. Such activities are cleaning, cooking, caring etc. For those countries for which results are based on HETUS data three different age profiles of household production are estimated: general housework, childcare and inter-household labour. General housework includes all the household production activities except childcare, while inter-household labour includes household activities carried out for other households, such as caring a person living in another household. For those countries for which results are based on MTUS data, we separately estimate the age profiles of general housework and childcare only, as inter-household production is not reported separately in the MTUS data, but already included in the household and childcare variables. 
Figure 7:

Age- and gender-specific time spent on household production, Sweden, Italy, France and Spain, early 2000s
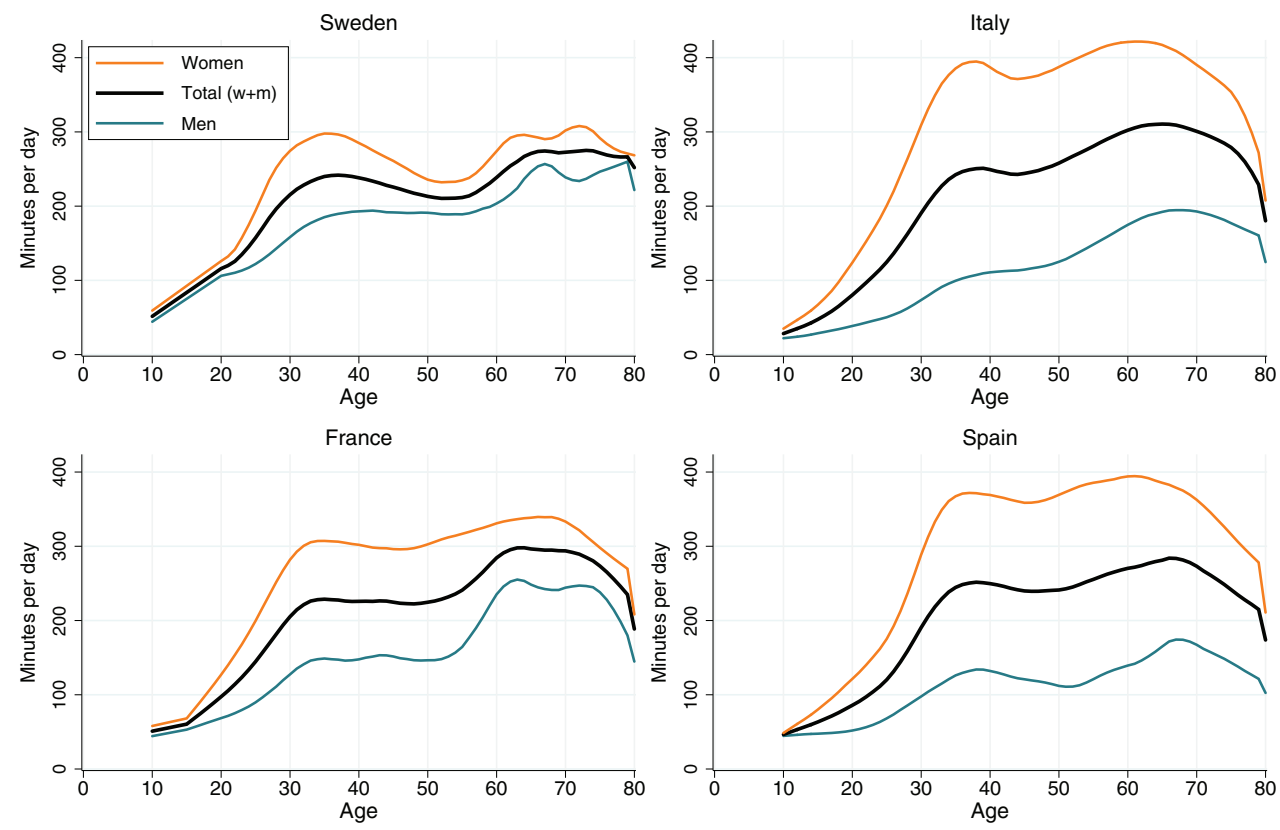

Source: Vargha et al. 2016 (retrieved from www.wittgensteincentre.org/ntadata).

After selecting the appropriate household activities in HETUS, the age- and gender-specific time spent on each activity during an average day can be directly retrieved from the HETUS dataset. When using MTUS data the gender-specific age profiles are estimated as age- and gender-specific averages of time spent on different household activities reported in the survey data. While the MTUS does not include information on the time spent on different activities for children under age 10, we can assume that these young children do not perform household activities. Even though the purpose of the NTTA is to estimate household production, the AGENTA Data Explorer also includes the time spent on other household activities, such as on paid work, education, leisure, and personal care.

Figure 7 shows the gender-specific age profiles of unpaid household work for four selected countries. We can see that in all of the countries, women devote considerably more time than men to unpaid household work, but that the gender differences vary greatly across the countries. For example, the differences are relatively small in Sweden, are relatively large in Italy and Spain, and are of moderate size in France. The average amount of time devoted to unpaid work peaks at childbearing ages (between ages 30 and 40), as people spend more time on child 
Figure 8:

Age-specific consumption of household labour, selected EU countries, early 2000s

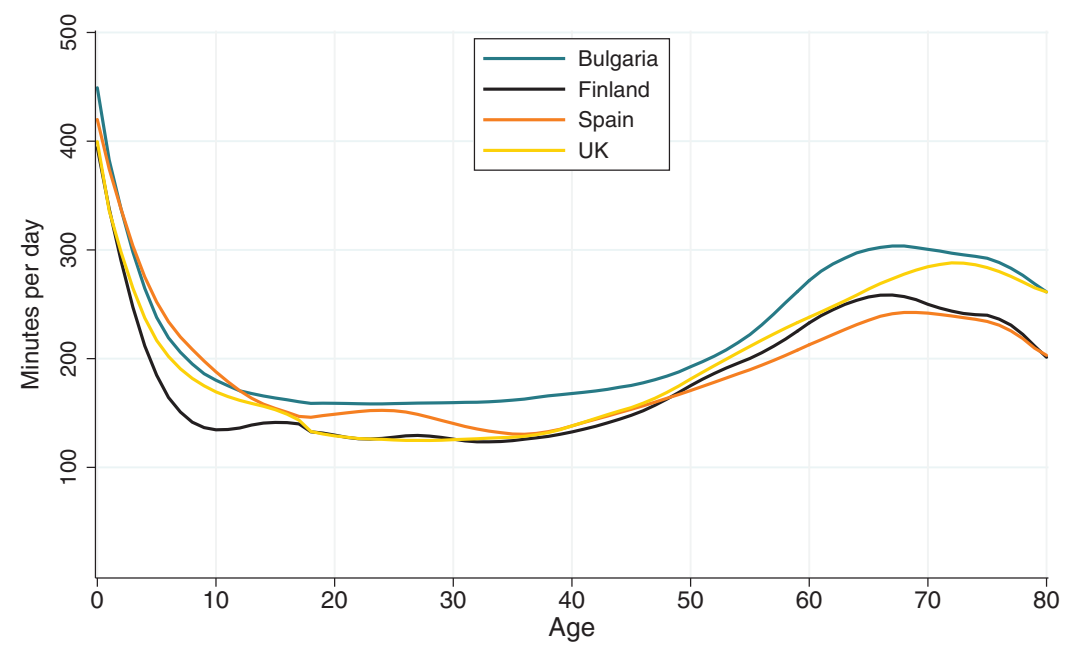

Source: Vargha et al. 2016 (retrieved from www.wittgensteincentre.org/ntadata).

care; and increases again at younger retirement ages, as people spend more time on household work.

\subsection{Consumption age profile}

The main contribution of the NTTA is that they allow for the estimation of the consumption of the goods and services produced through unpaid household labour. Because there are no survey data on the amounts of goods and services consumed that are generated by unpaid household labour, we need to allocate the goods and services produced using different allocation rules. We assume that all the household production, with exception of care, is consumed equally among the household members; and that care is distributed among the household members by age. Child care is consumed only by children. When there is only one child in the household, the allocation is straightforward. If there is more than one child in the household, the equivalence scale is used to allocate child care among the children. The equivalence scale is country-specific, and is generally based on the age of the youngest child living in the household. In the equivalence scale, the weights used to allocate child care within the household typically decrease by age, but depend on the number and the ages of the children. We assume that the equivalence scale is the same for both genders.

Figure 8 shows the age profiles of consumption of unpaid household work in four selected countries. In all of the countries, consumption levels are lowest during the 
Figure 9:

Daily per capita net time transfers by age and gender in hours in 14 European countries in early 2000 s

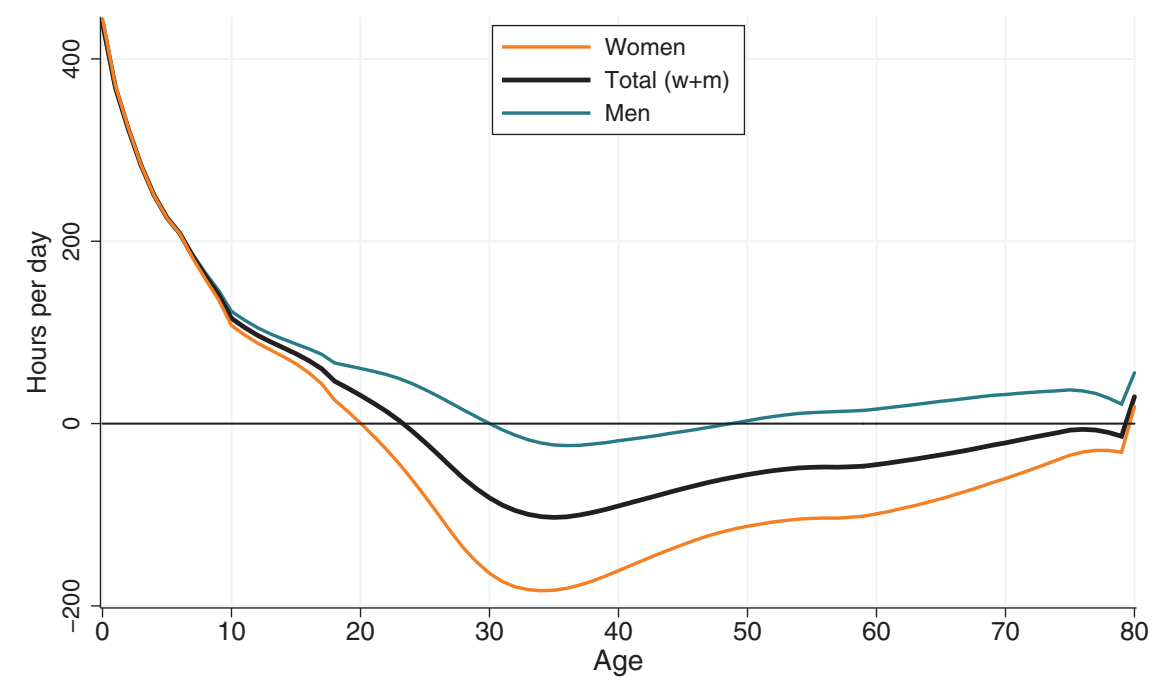

Source: Vargha et al. 2016 (retrieved from www.wittgensteincentre.org/ntadata).

prime ages, and are highest for new-borns. A peak is observed at young ages due to high levels of child care consumption, and again at retirement ages due to high levels of housework consumption (cleaning, cooking etc.). Bulgaria has the highest consumption levels at almost all ages. In Spain, consumption levels are relatively high at young ages, but are relatively low at older ages. This pattern is reversed in the UK. Among the selected countries, children consume the least amount of child care in Finland.

\subsection{Age profile of time transfers}

Time transfers in NTTA are a non-market counterpart of the LCD in the NTA dataset. They are defined as the difference between age-specific consumption and production of unpaid household work. The negative net transfers of unpaid household labour show the number of minutes of household labour that an individual transfers to other individuals (usually to the other household members). Thus, these transfers reflect the minutes an individual spends on household production that are not consumed by the individual him/herself. Figure 9 reveals that children and the elderly are net receivers of time transfers, whereas working-age individuals are net givers of time transfers. Since the level of household production is higher for women than for men, 
while levels of consumption are similar for men and women, in all of the countries, women are net givers of time transfers for a longer age span.

\subsection{Pricing household labour}

Another aim of the NTTA is to provide the monetary values of home production to allow for a direct comparison between the NTA and the NTTA estimates. The time spent on different economic activities is converted into monetary values using the input approach. Thus, we assign to different household activities the wages workers would receive for performing those activities on the market. These "specialist replacement wages" apply to different occupations and are country-specific. The wage levels are based on the 2002 wave of the structural statistics on earnings (SES). In the MTUS data, for which the estimated NTTA results go back to the 1970s, wage data from the "World Bank's World Development Report 2013: Occupational wages around the world" are used.

\section{Economic population pyramids}

The European NTA data can be used to visualise the relationship between age- and gender-specific economic behaviour, the demographic structure of the population, and the macro-economy. Economic population pyramids show the distribution of economic quantities by age groups and by gender. They reflect the size of the population, as well as the differences in economic behaviour across age groups and genders. Such population pyramids can be plotted using the data explorer at www.wittgensteincentre.org/ntadata.

Figure 10 shows an economic population pyramid for Sweden and Italy using consumption and labour income. To highlight the underlying age structure, the black line represents the shape of the demographic population pyramid. We can see that Italy has a pronounced baby boom at ages $40-45$, while the population structure in Sweden is more balanced. The figure also shows that baby boomers generate a large share of total labour income in Italy, and that women are much more likely to be engaged in paid work in Sweden than in Italy. Because the retirement age is higher in Sweden than in other countries, the Swedish population aged $60+$ contributes a much larger share of total labour income than their counterparts elsewhere.

Figure 11 shows the production and consumption of child care in Spain 2010 in terms of time. Children consume most of the child care they receive in their first years of life. Child care is mainly provided by the parents, most of whom are in the 30-40 age group. While women are less involved in paid work than men, they provide a much larger share of child care than men. 
Figure 10:

Consumption and labour income by age and gender in Sweden and Italy 2010

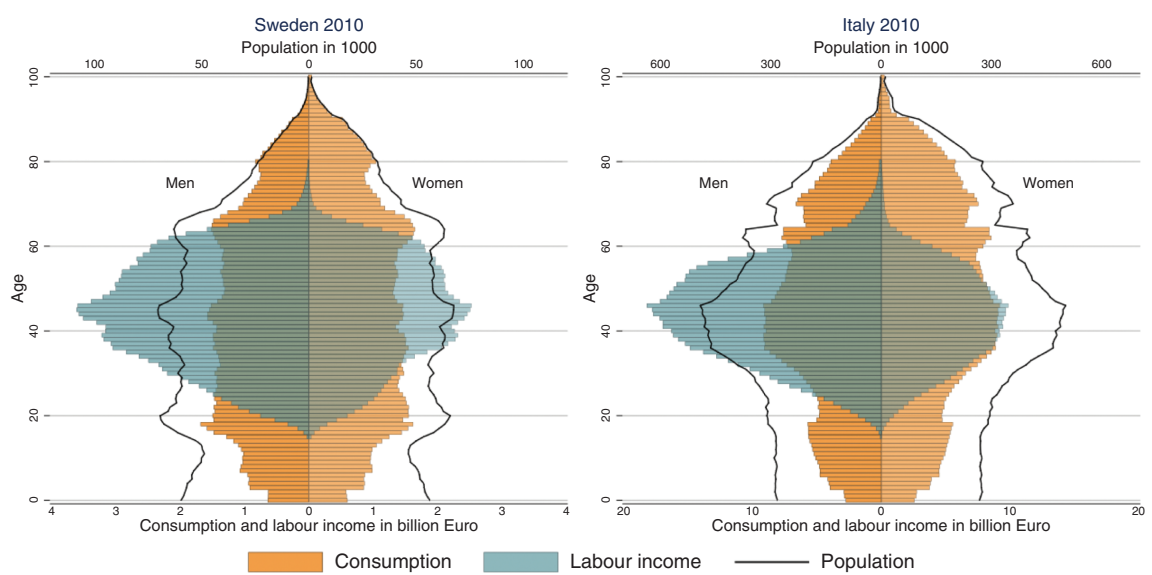

Source: www.wittgensteincentre.org/ntadata and Eurostat population data.

\section{Figure 11:}

Production and consumption of childcare by age and gender in Spain 2010

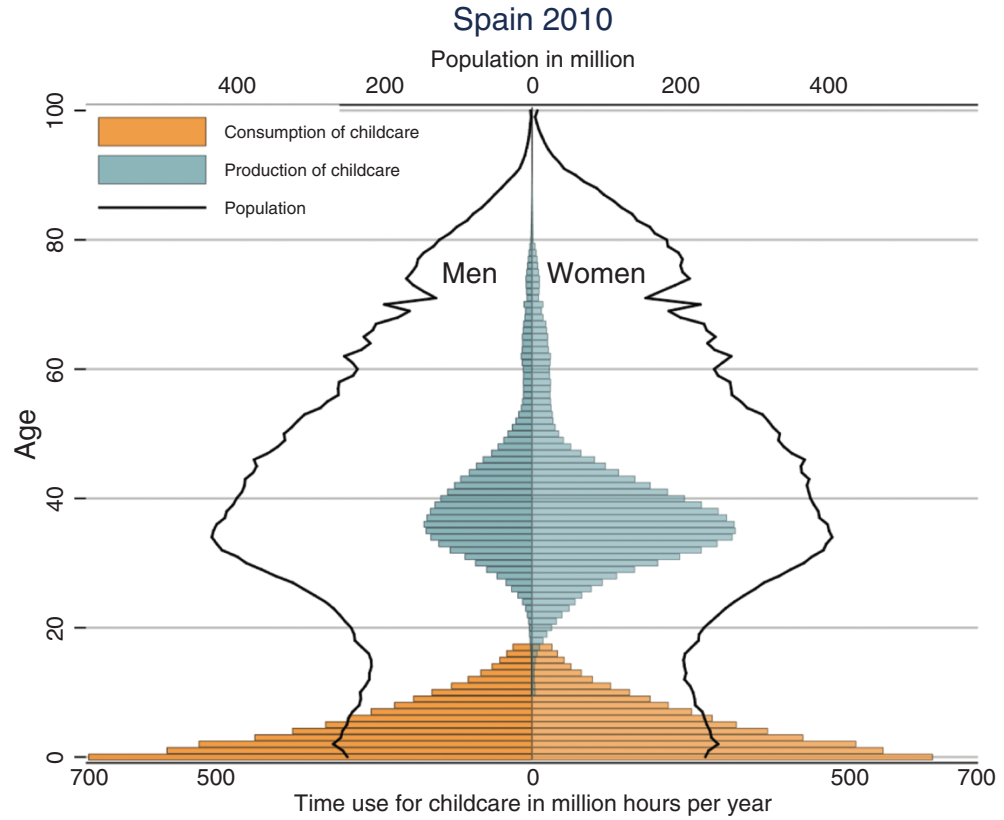

Source: www.wittgensteincentre.org/ntadata and Eurostat population data. 


\section{References}

d'Albis, H. and D. Moosa 2015. Generational economics and the national transfer accounts. Journal of Demographic Economics, 81(4): 409-441.

Deaton, A. 1997. The analysis of household surveys: a microeconometric approach to development policy. Baltimore, MD: The Johns Hopkins University Press.

Donehower, G. 2019. Methodology of the National Time Transfer Accounts. In Time use and transfers in the Americas: producing, consuming, and sharing time across generations and genders, ed. B. Piedad Urdinola and Jorge A. Tovar, 5-40. Cham, Switzerland: Springer Nature Switzerland. DOI: 10.1007/978-3-030-11806-8

European Commission 2012. 2012 Ageing report. Economic and budgetary projections for the 27 EU member states 2010-2060 (internal data).

Eurostat 2015. Eurostat Database. Retrieved from http://ec.europa.eu/eurostat/data/database.

Hammer, B., A. Prskawetz and I. Freund 2015. Production activities and economic dependency by age and gender in Europe: A cross-country comparison. The Journal of the Economics of Ageing 5: 86-97.

Istenič, T., B. Hammer, A. Šeme, A. Lotrič Dolinar and J. Sambt 2016. European National Transfer Accounts. Available at: http://www.wittgensteincentre.org/ntadata.

Lee, R. and A. Mason (eds) 2011a. Population aging and the generational economy: a global perspective. Cheltenham UK and Northampton MA: Edward Elgar.

Lee, R. and A. Mason 2011b. Lifecycles, support systems, and generational flows: patterns and change. In Population aging and the generational economy: a global perspective, eds R. Lee and A. Mason, 79-106. Cheltenham UK and Northampton MA: Edward Elgar.

Mason, A. and R. Lee 2011. Population aging at the generational economy: key findings. In Population aging and the generational economy: a global perspective, eds R. Lee and A. Mason, 3-31. Cheltenham UK and Northampton MA: Edward Elgar.

Mason, A., R. Lee, A.-C. Tung, M.-S. Lai and T. Miller 2006. Population aging and intergenerational transfers: Introducing age into national accounts: National Bureau of Economic Research.

United Nations 2013. National Transfer Accounts manual: Measuring and analysing the generational economy. New York: United Nations.

Vargha, L., A. Šeme, R. I. Gál, B. Hammer and J. Sambt, 2016. European National Time Transfer Accounts. Available at: http://www.wittgensteincentre.org/ntadata. 


\section{Appendix}

The European NTA 2010 data provide comprehensive and detailed age- and genderspecific economic data on income, transfers, consumption and saving in the year 2010 for 25 EU countries. These data are predestined to study the relationship between age, economic activity and the organization of intergenerational transfers. Explore and download European NTA with the NTA 2010 data explorer (see Figure A.1) available at http://dataexplorer.wittgensteincentre.org/nta/.

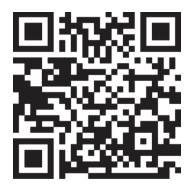

Figure A.1:

The NTA Data Explorer

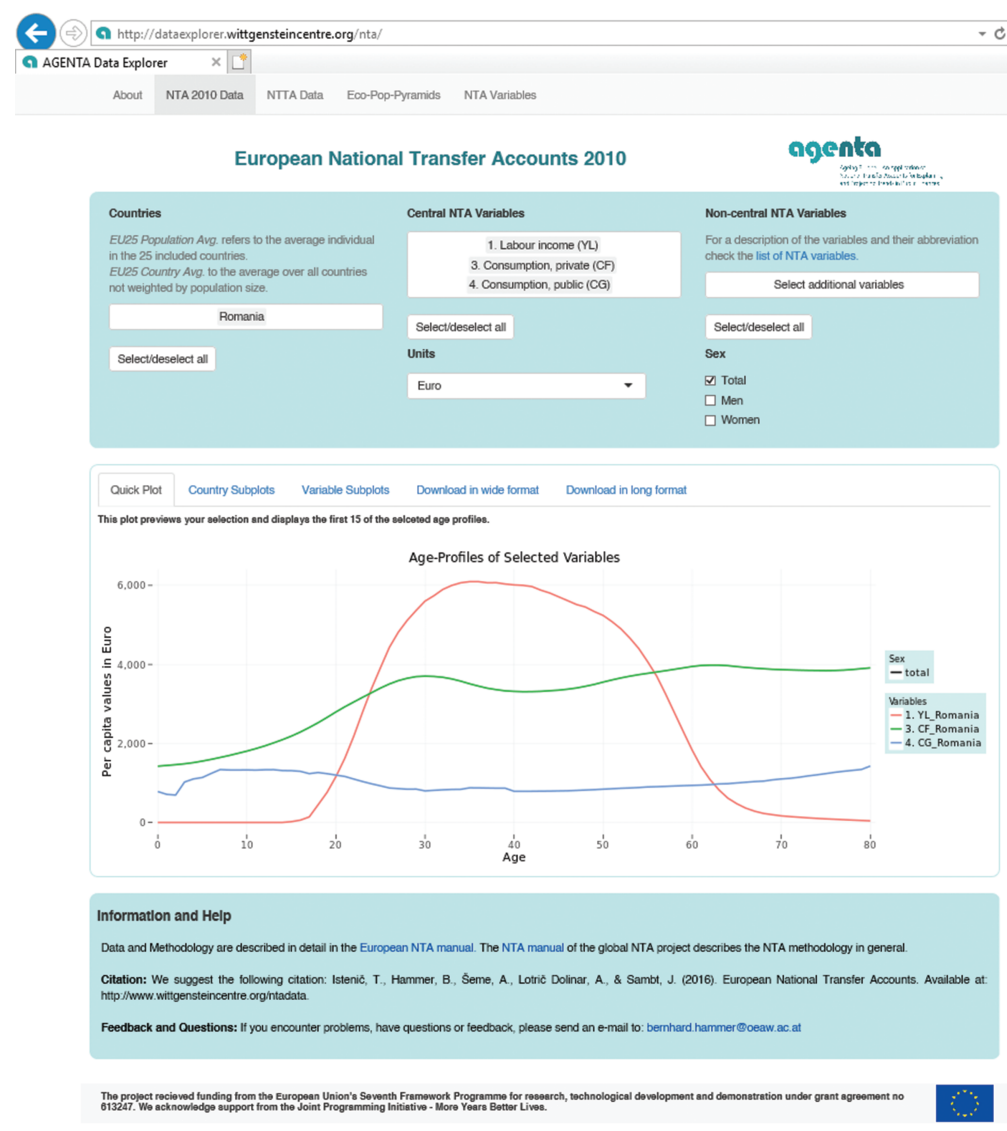


National Time Transfer Accounts (NTTA) include age- and gender-specific data on the production, consumption and transfers of services that are produced through unpaid work and not captured in National Accounts. European NTTA are based on time use data from the Harmonized European Time Use Survey (HETUS) and the Multinational Time Use Survey (MTUS). Explore and download European NTTA using NTTA data explorer (see Figure A.2) available at http://dataexplorer. wittgensteincentre.org/nta/.

\section{Figure A.2:}

\section{The NTTA Data explorer}

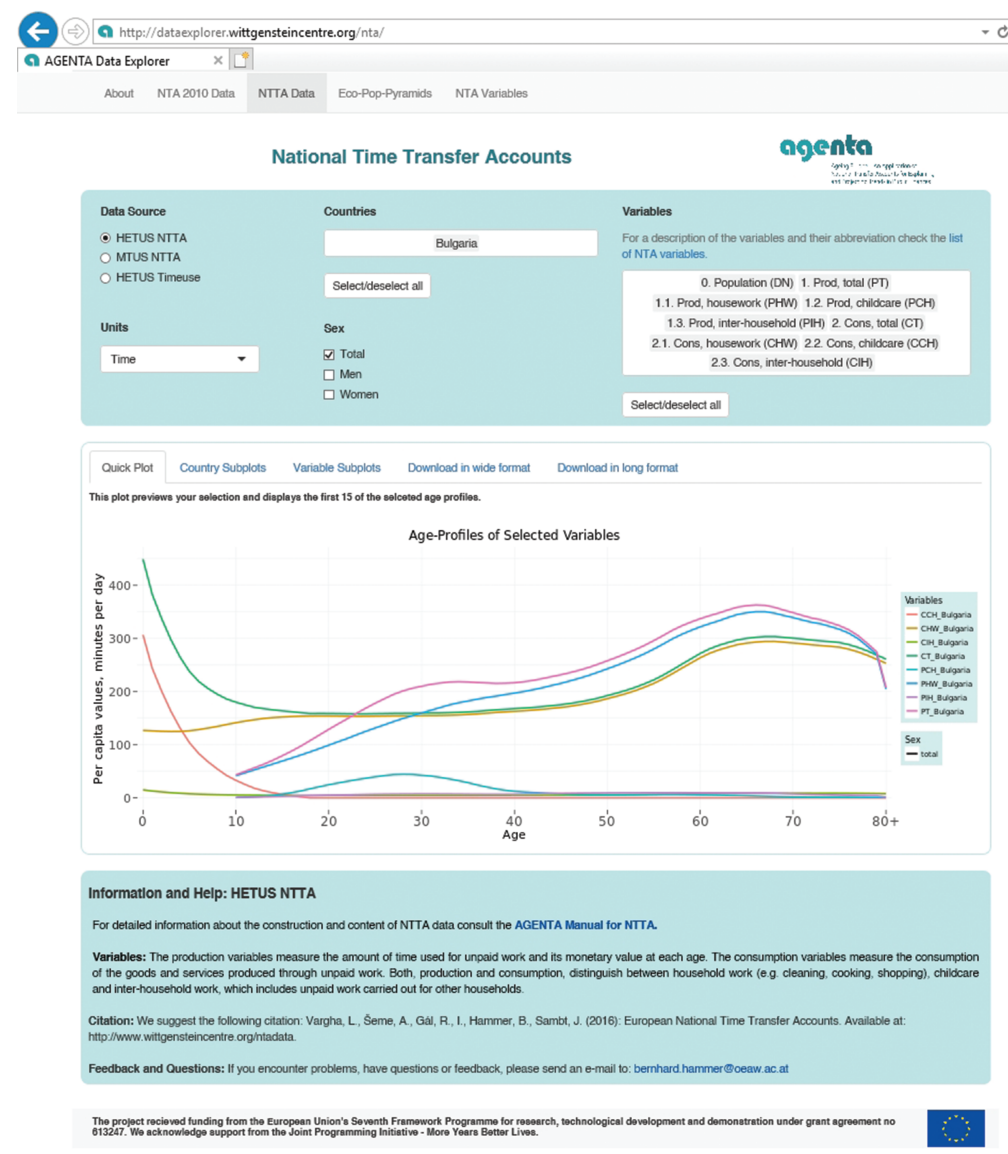

